Published in final edited form as:

Dev Psychol. 2005 September ; 41(5): 747-759. doi:10.1037/0012-1649.41.5.747.

\title{
Social Competence in Children of Alcoholic Parents Over Time
}

\author{
Andrea M. Hussong, \\ Department of Psychology, University of North Carolina at Chapel Hill \\ Robert A. Zucker, \\ Department of Psychiatry and Addictions Research Center, University of Michigan \\ Maria M. Wong, \\ Department of Psychiatry and Addictions Research Center, University of Michigan \\ Hiram E. Fitzgerald, and \\ Department of Psychology, Michigan State University \\ Leon I. Puttler \\ Department of Psychiatry and Addictions Research Center, University of Michigan
}

\begin{abstract}
In the current study, the authors tested the hypothesis that children of alcoholic parents (COAs) show deficits in social competence that begin in early childhood and escalate through middle adolescence. Teachers, parents, and children reported on the social competence of COAs and matched controls in a community sample assessed from ages 6 to 15. Hierarchical linear growth models revealed different patterns of change in social competence across development as a function of the reporter of various indicators of competence. Moreover, female COAs showed deficits in social competence in early childhood that receded in adolescence and that varied across subtypes of parent alcoholism. Implications of these findings for understanding the development of social competence in children, and at-risk children in particular, are discussed.
\end{abstract}

\section{Keywords}

parent alcoholism; social competence; social development; peer relationship; at-risk youth

\begin{abstract}
The development of social competence is a fundamental aspect of children's adjustment. Children with friends have greater academic success and are less likely to be aggressive, lonely, and depressed compared with children without friends (Parker \& Asher, 1987, 1993; Rockhill, 1995). Moreover, both lower peer acceptance and greater peer rejection in preadolescents have been linked to lower feelings of self-worth and psychopathology in adulthood (Bagwell, Newcomb, \& Bukowski, 1998), demonstrating the potential long-term consequences of social competence.

Less understood than the impact of social competence, however, is the development of social competence itself. Theories of social competence posit that individual children change over time in their social functioning, suggesting a pattern of intraindividual variability, and that children vary from one another in the extent to which their social competence changes
\end{abstract}

\footnotetext{
Copyright 2005 by the American Psychological Association

Correspondence concerning this article should be addressed to Andrea M. Hussong, Department of Psychology, University of North Carolina at Chapel Hill, College of Arts and Sciences, Campus Box 3270, Davie Hall, Chapel Hill, NC 27599-3270.

hussong@unc.edu.
} 
over time, suggesting a pattern of interindividual variability (e.g., Berndt \& Burgy, 1996; Eccles et al., 1989). Unfortunately, previous studies primarily use cross-sectional or shortterm (i.e., two time point) longitudinal designs that do not permit distinctions between these two types of change over time. Greater use of high-risk, prospective research designs with multiple assessment periods overcomes this limitation (Curran, Bollen, Paxton, Kirby, \& Chen, 2002; Kalverboer, 1988; Ledingham, 1990). High-risk designs allow us to better model and understand low-base rate behaviors, such as child maladjustment and social deficits, and multiple assessment designs can disentangle intraindividual and interindividual change by using recent statistical advances (Raudenbush, 2001).

One group of children who show an elevated risk for a broad range of problems is children of alcoholic parents (COAs; West \& Prinz, 1987). Research concerning COAs has largely focused on risk for maladaptive behaviors in this population, indicating that COAs are more likely to show internalizing symptoms, aggression, and substance abuse than their peers (Chassin, Rogosch, \& Barrera, 1991; Puttler, Zucker, Fitzgerald, \& Bingham, 1998; Sher, 1991). Little attention has been given to whether COAs show deficits in adaptive behavior in addition to such excesses in maladaptive behavior. To address these issues, the current study examined individual trajectories of social competence spanning the ages of 6 to 15 in a highrisk sample of COAs and matched controls.

\section{The Development of Social Competence}

Competence is typically defined as a global construct in which "the competent individual is one who is able to make use of environmental and personal resources to achieve a good developmental outcome" (Waters \& Sroufe, 1983, p. 81). Although studies vary widely in operationalizations of social competence, making and maintaining friendships, fostering popularity and social acceptance, and developing skills in relating to peers are consistent markers of the construct (Berndt \& Burgy, 1996; Rose-Krasnor, 1997). Moreover, these three dimensions are often intertwined in assessments of overall social competence (Bracken, 1992; Harter, 1982; Marsh \& O’Neill, 1984).

Such measures have been used to assess social competence across a variety of reporters, including children, parents, teachers, and peers, though few studies actually test patterns of intraindividual variability, or trajectories, of social competence over time. Cole, Maxwell, et al. (2001) examined change over time in self-reported social competence among 3rd to 11th graders as assessed by Harter's $(1982,1985)$ social concept measure. In this study, normative trajectories of self-reported social competence increased until 7 th grade, when they began to plateau. Gender differences emerged in social self-concept in high school, with boys showing greater social competence. Chan, Ramey, Ramey, and Schmitt (2000) also examined change over time in social competence through parent and teacher reports in a sample of kindergarteners who completed four annual assessments. Different patterns of intraindividual change emerged as a function of observer, such that parent reports increased more from kindergarten to 2nd grade than from 2nd grade to 3rd grade, evidencing a curvilinear increase over time. However, teacher reports showed a linear decrease in social competence over time. Gender differences in this study indicated that girls showed greater social competence than did boys in teacher reports but not in parent reports. Together, these findings suggest that both intraindividual patterns of change in social competence over time as well as gender differences in social competence are likely to vary by reporter, which presumably in part reflects the social presentation differences found in these various contexts.

Previous studies provide support for interindividual stability in social competence, such that those children who are most competent at one age are likely to be the most competent at 
another (Eccles et al., 1989). For example, Masten et al. (1995) showed prospective consistency (with a stability of .45 ) in a latent factor of social competence composed of child self-reports and peer nominations in late childhood and of child and parent interviews in late adolescence. Parent and teacher reports, however, may show a different trend. On the basis of these findings, we used a sample of children aged 6 to 15 to test gender differences in both intraindividual and interindividual change in various indicators of social competence assessed over time through multiple reporters (Cole, Jacquez, \& Maschman, 2001; Eccles et al., 1989; Wigfield, Eccles, Maciver, Reuman, \& Midgley, 1991).

\section{COAs}

Little research has directly examined the social competence of COAs, although peer relationships are thought to play a key role in many theories of psychopathology to which this population is prone (Coie, Belding, \& Underwood, 1988; Dishion, Capaldi, Spracklen, \& Li, 1995; Oetting \& Beauvais, 1987). Early deficits in social skills, such as having few friends and less group participation, are associated with later problems in acceptance by non-deviant peers and forming friendships with them (Parker, Rubin, Price, \& DeRosier, 1995). As such, social deficits at school entry may be an early warning sign that intervention is needed (Ladd, 1990).

Little is known about social competence in COAs during childhood and adolescence. On the basis of the retrospective reports of college students, Segrin and Menees (1996) found no differences in the social skills (i.e., communication-expressivity and sensitivity) of COAs and their peers in early childhood, although problems with retrospective reports and child reports of parent alcoholism weakened this study. More broadly, social skill deficits have been found in children of parents with psychiatric problems. For example, Larsson, Knutsson-Medin, Sundelin, and Trost von Werder (2000) reported greater problems in peer and sibling relationships among children of parents admitted to a Swedish psychiatric unit compared with similar-aged schoolchildren. Chan et al. (2000) also found social skills deficits, as reported by teachers, in children of parents with lower education and income, which are often associated with parent alcoholism, although no differences in social skills were noted in parent reports.

Although a coherent picture has not emerged from the impoverished literature to date, we postulate that differences in social competence may vary within COAs given the substantial heterogeneity of stress and conflict, as well as genetic liability, within these families (Puttler et al., 1998; Wong, Zucker, Fitzgerald, \& Puttler, 1999). We expected those COAs with two, rather than one, alcoholic parent may not benefit from the potential compensating protection offered by a nonalcoholic parent and thus would show greater social competence deficits (as suggested by Werner, 1986, though also see Curran \& Chassin, 1996). In addition, children whose parents have experienced alcoholism more recently, as opposed to those whose parents were recovered, may also experience more acute chaos, stress, and unpredictability in the home environment, also increasing risk for social competence deficits (Pillow, Barrera, \& Chassin, 1998). Finally, we examined social competence deficits in children with alcoholic mothers versus fathers. Given alcoholic parents' frequent role as primary caretakers and the impact of assortative mating, in which a family with an alcoholic mother often also has an alcoholic father, children of alcoholic mothers may be expected to show greater social competence deficits. However, paternal alcoholism has also been associated with greater risk for behavioral dysregulation and difficult temperament, perhaps related to a genetic liability, each of which may increase risk for social competence deficits as well (Tarter et al., 1999). As such, we explored the relation between maternal and paternal alcoholism and children's social competence over time. 
In sum, we examined interindividual and intraindividual changes in children's trajectories of social competence over time as well as how these trajectories relate to parent alcoholism in a heterogeneous sample of COAs and matched controls. Given the well-documented heterogeneity among alcoholic adults, to better understand whether such early social skill deficits are equally evident across this risk group, we tested whether evidence for social deficits varied as a function of the number of alcoholic parents in the family, the recency of the parent's alcoholism, and the gender of the alcoholic parent. Moreover, we considered the potential for gender differences, evident in normative samples, within each of these hypotheses. Although multiple reporters of social competence were examined, reporters varied in the indicators of social competence assessed. As such, cross-reporter comparisons are interpreted with respect to potential differences as a function either of reporter or of the variation in subcomponents of social competence across measures assessed.

\section{Method}

\section{Participants}

Families in the current study are participants in an ongoing, prospective, multiwave study that is tracking a community sample of families with high levels of alcohol use disorder, along with a community contrast sample of families drawn from the same neighborhoods who do not show the high-substance abuse profile (Zucker \& Fitzgerald, 1991; Zucker et al., 2000). Recruitment followed a high-risk design in which children of alcoholic and nonalcoholic parents were targeted through a rolling recruitment procedure. The sample in the current study can be characterized by three cohort assessments (see Figure 1). In the first cohort, alcoholic fathers were identified through district courts and invited to participate if they had a male biological child aged 3-5, were Caucasian, lived with the child, and were coupled with the child's biological mother (whose substance abuse was not constrained). Exclusion criteria included the presence of fetal alcohol syndrome in the target child. (Fetal alcohol syndrome was assessed by master-level clinical psychologists trained in early child assessment who had experience using the Fetal Alcohol Study Group guidelines [Sokol \& Claren, 1989] to evaluate facial dysmorphology, growth retardation, etc. to make the classification. For more details see Bingham, Fitzgerald, Fitzgerald, \& Zucker, 1996, and Noll, Zucker, Fitzgerald, \& Curtis, 1992). A second subset of alcoholic fathers was uncovered during neighborhood canvassing for contrast families (see below). This group also needed to have at least 1 son between 3 and 5 years of age and have a father coupled with the boy's biological mother, whose drug involvement was also free to vary. Parents in the contrast group were recruited through canvassing in the same neighborhoods where the alcoholic families lived; parents were required to show an absence of lifetime history of substance abuse or dependence and were matched to alcoholic families on the basis of neighborhood residence and child age. A total of 335 boys (from 335 families) participated in this first cohort assessment when the male target child was age 3-5 years (Wave 1). At the time these data were analyzed, families had been assessed over four waves of data collection, separated by 3-year intervals. A total of 231, 249, and 248 boys had reports on their functioning available at Waves $2-4$, respectively, yielding an overall participation rate of $88 \%$ for boys with at least two waves of data in the sample (see Zucker et al., 2000, for a detailed description of sample criteria and recruitment procedures).

A second cohort involved girls in the Cohort 1 families who were recruited when Cohort 1 boys were at Wave 2 . Because Cohort 1 inclusion criteria involved having families with at least 1 male child with no restriction on the presence of other children, fewer families had female children. To compensate for these target families having fewer girls than boys, we used a broader age range to recruit girls, and girls were enrolled if they were aged 3-11, with those aged 3-5 receiving the Wave 1 battery, those aged 6- 8 receiving the Wave 2 battery, and those aged $9-11$ receiving the Wave 3 battery. Similarly, the third cohort 
contained all additional siblings of the male target child in Cohort 1 who were aged 3-11 at the time of data collection, with assessment batteries structured by age as for Cohort 1 . The siblings in Cohorts 2 and 3 were reassessed in all subsequent waves of data collection and received measures that paralleled the male target children in Cohort 1 on the basis of age of assessment. Because children in Cohorts 2 and 3 were recruited later in time and could enter the study at older ages, fewer waves of data collection are available for these participants by design. A total of 149 girls (from 149 families) comprised Cohort 2 and an additional 69 siblings (from 62 families) comprised Cohort 3.

Across all three cohorts, 553 children from 335 families were eligible for inclusion in the current analyses. However, to ensure similar samples for analyses across the multiple reporters of social competence, we constrained the sample to those children with parent alcoholism data and at least one observation (i.e., wave of assessment) on each of the three social competence outcome variables. The resulting analysis sample included 373 children from 265 families ( 32 female controls, 78 female COAs, 63 male controls, and 200 male COAs; aged 2-15 across waves; participants were predominantly [98\%] Caucasian; parent education ranged from $8 \%$ of families in which neither parent had a high school education to $24 \%$ of families in which at least one parent was a college graduate; no information on disability status or sexual orientation was available). Although all children were included in analyses for the three social competence outcomes, the pattern of missing data within the sample varied by outcome, such that a different number of repeated observations were available for each outcome. Specifically, 203 children had all three assessments (at ages 6$8,9-11$, and 12-15) of parent-reported social competence available, 113 had two waves, and 57 had a single wave of data. For teacher-reported social competence, 78, 168, and 129 had three, two, and one wave of data available, respectively, and 116, 189, and 68 had three, two, and one wave of self-reported social competence data, respectively. Because of this data structure, we used missing data techniques in the statistical analyses that are capable of incorporating diverse patterns of missingness without producing biased findings (see Results).

Two sets of attrition analyses were conducted. We tested whether the 180 children excluded from all analyses because of missing reports of all social competence variables differed on child gender and parent alcoholism from the 373 retained for analyses. No differences were found on parent alcoholism status, $\chi^{2}(1, N=553)=0.12, p=.73$, nor on participant gender, $\chi^{2}(1, N=553)=1.98, p=.16$. We also estimated the effects of missing data, whether because of attrition or design, by calculating the number of missing variables out of all central variables (the three social competence variables at Waves 2-4, COA, and child's gender) for each of the 373 participants included in analyses. Correlations between the number of missing variables and the nine continuous outcome measures (where present) revealed no significant associations. $T$ tests showed that COAs were more likely to have missing data than their peers, $t(371)=-2.18, p<.05$, and, as expected by design, girls had more missing data than boys, $t(371)=4.24, p<.001$. These missing data effects suggest some potential bias if listwise deletion procedures were used in analyses; thus, missing data were addressed through the use of appropriate analytic techniques that retained all 373 participants in statistical procedures (see Results).

\section{Procedure}

Each family completed a primarily in-home assessment conducted by trained staff who were blind to family diagnostic status (Wong et al., 1999). Although protocol length varied by wave of assessment, parent assessments typically involved 9-10 hr of data collection, and child assessments were typically $7 \mathrm{hr}$, each spread over seven testing sessions. Families were compensated $\$ 300$ for their involvement if the assessment was carried out on a 1-child family and $\$ 375$ if 2 children were involved. A variety of age-appropriate tasks (e.g., 
questionnaires, semistructured interviews, and interactive tasks) were administered. As special arrangements were made to assess families who had relocated, no families were lost for this reason. During the age 6-8 assessment, parents were asked to provide the name of the child's school, the child's grade, and the name of the child's teacher. Parents were also asked to sign a release form. This form was mailed to the child's teacher along with a letter of introduction, three surveys about the child, and a $\$ 10$ check as compensation. Similar teacher data were obtained in assessments for ages 9-11 and 12-15. At the point when the multiple-teacher class schedule began, the child was asked to identify the teacher with whom he or she spent the most time (ruling out home room and physical education class).

\section{Measures}

Parent alcoholism (alcohol use disorder)—Parental alcohol use disorder at Wave 1 was assessed by the Diagnostic Interview Schedule-III (Robins, Helzer, Croughan, \& Ratcliff, 1980), the Short Michigan Alcohol Screening Test (Selzer, Vinokur, \& van Rooijan, 1975), and the Drinking and Drug History Questionnaire (Zucker, Fitzgerald, \& Noll, 1990). On the basis of information collected by all three instruments, a diagnosis of alcohol use disorder (lifetime as well as past 3 years) was made by a trained clinician using Diagnostic and Statistical Manual of Mental Disorders (4th ed.; American Psychiatric Association, 1994) criteria. The availability of three sources of information collected over three different sessions, separated in some instances by as much as several months, served as an across-method validity check on respondent replies. Given the volume of material collected as well as the spacing between sessions, it is unlikely respondents would recall their specific replies. In cases of discrepant information, the data represented by the majority of information sources were used in establishing the diagnosis. Interrater reliability for the diagnosis was excellent $(\kappa=.81)$.

In the current analyses, children were coded as having an alcoholic parent if either parent met lifetime criteria for alcohol abuse or dependence at the age 6-8 assessment period, which is the first assessment period for social competence outcomes. (Lifetime parent alcoholism diagnoses were combined with subsequently assessed diagnoses in the past 3 years to determine whether either parent had ever met criteria for an alcohol abuse or dependence disorder when a given child was assessed at ages 6-8.) Because lifetime parent alcoholism diagnoses are a function of time and may differ for siblings within the same family depending on their ages, all indicators of parent alcoholism were treated as individual-, rather than family-level, variables in the current analyses.

Three indices of parent alcoholism coded for heterogeneity within this risk indicator. On the basis of the lifetime indicator of parent alcoholism, one set of indicators coded separately for maternal ( $n=128$ of 373 participants) and paternal ( $n=267$ of 373 participants) alcoholism. A second indicator was formed by a set of dummy variables that distinguished between families without an alcoholic parent $(n=95)$, with a recently alcoholic parent (within the past 3 years prior to the age 6-8 assessment; $n=206$ ), and with a recovered alcoholic parent $(n=72)$. A third indicator summed the number of alcoholic parents present in a family ( 95 with zero alcoholic parents, 161 with one alcoholic parent, and 117 with two alcoholic parents).

Social competence-Reports of social competence were assessed by self-, parent, and teacher report. See Table 1 for descriptive statistics of outcome measures by child age.

Children completed Harter's Self-Perception Profile (Harter, 1985, 1988) measure in Waves 2-4. In Waves 2-3, the children were aged 6-11 and the child version of this questionnaire was administered, whereas in Wave 4 children were 12-15 and the adolescent version was used. To create a consistent scale across waves for use in longitudinal analyses, we retained 
only similar items across the two versions to avoid measurement differences over time (similar to Cole, Jacquez, \& Maschman, 2001; sample items assess finding it hard to make friends and having lots of friends). The response scale for these items followed the original format, ranging from 1-4. Retained items resulted in a five-item scale assessing selfreported social competence at each of the three waves $(\alpha=.65, .72$, and .81 for boys and . $61, .74$, and .79 for girls at Waves $1-3$, respectively).

The teacher report measure was created using two items from the School Performance Questionnaire (Piejak, Fitzgerald, Zucker, \& von Eye, 2004) and nine items concerning classroom activity from the Revised Class Play Questionnaire (RCPQ; Fitzgerald et al., 1993; Noll et al., 1992). Items from the School Performance Questionnaire were chosen to capture teacher report of social competence (i.e., two items rating social development and child likability, respectively), whereas those from the RCPQ were chosen on the basis of previous analyses by Piejak et al. (2004) to construct a social competence measure from this instrument (sample items assess ease of making friends and having many friends). Both instruments shared a 5-point response scale. Exploratory factor analyses of these 11 items most strongly supported a two-factor solution as indicated by incremental variance indicators and the principle of simple structure (Loehlin, 1992). Using promax rotation, we found similar solutions for each of three waves of data analyzed. The first factor contained seven items from the School Performance Questionnaire and RCPQ that reflected having lots of friends and being popular, and the second factor contained items from the RCPQ that reflected the development of leadership skills. For purposes of the current study, a single scale based on the average of seven items on the first factor was retained as the teacher report variable for social competence $(\alpha=.88, .89$, and .88 for boys and $.83, .90$, and .90 for girls at Waves 1-3, respectively).

Parent report items of social competence were derived from the competency subscales of the Child Behavior Checklist (Achenbach, 1991). Four items assessed through mother and father report of the number of close friends, time spent with friends, and getting along with siblings and other kids formed this scale. Available parent reports were combined into a single measure (across-reporter correlations ranged from .41 to $.56, p<.001$, over waves). All items were rated on a 3-point scale, except for the number of friends that was collapsed to three categories $(0-1,2-3,4$ or more) as guided by the observed distribution. These eight items were averaged to form a parent report scale for social competence $(\alpha=.62, .54$, and . 77 for boys and $.55, .67$, and .64 for girls at Waves $1-3$, respectively).

\section{Results}

We used a series of hierarchical linear models (HLM; Raudenbush \& Bryk, 2002) to test whether heterogeneity in parent alcoholism predicted three indicators of social competence. These models allowed us to account for the three levels of structure in these data (i.e., repeated time points nested within individuals and siblings nested within families) while examining longitudinal relations between parent alcoholism and trajectories of social competence over time. Another benefit of the HLM approach is that the empirical Bayes estimation procedures permit inclusion of participants with incomplete data over time. The approximately normal distribution of our outcome measures permitted linear estimation methods, although robust test statistics are reported here. Outlier analyses revealed no significant influential cases in the data.1

\section{Trajectories of Social Competence}

Prior to testing relations between various predictors and trajectories of social competence over time, we conducted separate unconditional growth models to examine the trajectories underlying each of the three social competence outcomes. Because of both the differences in 
the assessment schedule as a function of gender and the various patterns of missingness in the data, we elected to analyze the data as a cohort sequential design, with age of the child rather than wave of assessment as a marker of time, such that measures of social competence began at age 6 and ended at age 15. Means for each social competence index as a function of age are presented in Table 1. As these means indicate, we would expect our unconditional HLM analyses to show an increase over time in self-reported social competence, a slight decrease over time in teacher reports, and little change over time in parent reports.

The unconditional linear growth model comprises four key parameters that define the average or group trajectory for a given outcome as well as individual variability in the set of trajectories constituting the sample. The average trajectory is defined in terms of a mean intercept and slope, modeled as fixed effects. Interindividual variability across participants' trajectories is then reflected in variation among participants' trajectories from the mean intercept and mean slope, modeled as random effects. For the current analyses, we coded the fixed intercept to reflect the average level of social competence for 6-year-olds in the sample and the fixed slope to reflect the amount of change in social competence per year over observed assessments from age 6 to 15. As such, the random intercept reflects the extent to which participants differ from one another in their social competence at age 6 , and the random slope reflects the extent to which participants differ in the rate of change characterizing their social competence over time. Because the current study involves a threelevel design, in which siblings are nested within families, we also modeled intrafamilial variability in the repeated observations of social competence through a random family-level intercept. 2 Results for the three models are reported in Table 2.

For self-reported social competence, significant fixed-effect components of the trajectories indicated that average social competence at age 6 was 2.90 (i.e., the intercept), with a significantly increasing linear trend of .06 per year (i.e., the slope), such that average levels of self-reported social competence increased from 2.90 at age 6 to 3.44 over the course of the 9-year interval. A significant random effect in the intercept was also found, indicating that participants differed from one another in their self-reported social competence at age 6 . Moreover, a marginally significant random effect in the slope indicated some confidence that individuals varied from one another in the extent to which their social self-competence scores change over time.

For the parent report model, the significant fixed intercept indicated an average of 2.30 for social competence at age 6 , but a nonsignificant fixed slope indicated no change or a flat average trajectory of social competence over time. Significant random effects, however, showed reliable individual differences in both the levels of social competence at age 6 (as reflected in the random intercept term) and in the rate of change in social competence over time (as reflected in the random slope term). Thus, although the average group trajectory for

\footnotetext{
${ }^{1}$ To examine the influence of potential outliers, we performed individual regression analyses for each participant to derive an estimated intercept and slope for his or her trajectory. On the basis of these trajectory parameters, we estimated time-specific measures for each social competence indicator. Potential outliers were identified as (a) participants with large discrepancies between observed and estimated time-specific measures for a given social competence indicator and (b) large estimated intercept or slope factors with respect to the group mean. Unconditional HLM analyses were reestimated dropping these potential outliers and compared with results when these cases were included. No substantive changes in trajectory parameters resulted from dropping these cases, indicating that they were not influential. As such, all cases were retained in analyses presented here.

${ }^{2}$ Intrafamilial variation is modeled in the social competence outcomes to correct standard errors for nesting of siblings within families in the study design. However, intrafamilial variation is not central to the questions of the current study and thus will not be discussed further. Small numbers of children within families (ranging from 1 to 4 ) limit our ability to interpret the intrafamilial variation effects meaningfully. In HLM reduced-model notation, the final models were estimated as follows: $Y_{t i k}=\left(\gamma_{000}\right)+\left(\beta_{10 k} * A G E_{t i k}\right)+\left(U_{00 k}\right.$ $\left.+r_{0 i k}+r_{l i k}+e_{t i k}\right)$, where $Y$ represents the outcome, $t$ represents time, $i$ represents individual children, $k$ represents family, $\gamma 000$ represents the fixed intercept, $\beta 10 k$ represents the fixed slope, $U_{00 k}$ represents the random effect for intrafamilial variation in social competence, $r_{0 i k}$ represents the random effect for the intercept, $r_{1 i k}$ represents the random effect for the slope, and $e$ represents residual variance.
} 
parent-reported social competence is a flat line reflecting a consistent level of 2.30, individual participants had trajectories that reliably varied from one another in both their intercepts and slopes.

Finally, in the teacher report model, a significant fixed effect of the intercept and a nonsignificant fixed effect of the slope were found. This average trajectory was characterized by a 3.49 level of social competence at age 6 and by no change in social competence over time. Significant individual differences were found in the random intercept for this model, such that participants reliably differed from one another in their age 6 levels of teacher-reported social competence but not in the random effect for the slope parameters.

\section{Parent Alcoholism and Social Competence}

Three models for each social competence outcome, or a total of nine models, were conducted for the effects of heterogeneity in parent alcoholism on trajectories of social competence. For each model, a series of individual (or Level 2) predictors were added to the model that included indicators of parent alcoholism, child gender, and the interaction between the two. These variables were included in predictions of the random intercept and the random slope of the social competence trajectories. 3 This model allowed us to examine whether boys and COAs show early decrements in social competence (in the prediction of the random intercept term) and escalating patterns of social competence problems over time (through their interaction with age in predicting social competence). These models were tested hierarchically, such that an initial model tested the main effects of parent alcoholism and child gender on the social competence trajectories and a second model tested the additional effect of the interaction term. Three sets of predictors were used to test for parent alcoholism effects where heterogeneity in this risk factor was modeled first as a function of gender of the alcoholic parent (i.e., the unique effects of having an alcoholic father and/or an alcoholic mother), the recency of parent alcoholism, and the number of alcoholic parents in the family. Results from these models are reported in Table 3.

In the self-reported social competence model, the interaction between having an alcoholic father and the child's gender was a significant predictor of initial levels of social competence (i.e., intercepts). No other effects of paternal or maternal alcoholism were found. To better understand this interaction, we probed mean trajectories of self-reported social competence as a function of child's gender and parent alcoholism (techniques for

\footnotetext{
${ }^{3}$ Although some researchers suggest that nonsignificant variance in the random slopes precludes the inclusion of predictors of the random slopes, more recent suggestions have indicated that such predictors are indeed appropriate and simply reflect the interaction of a given predictor with time that might be modeled as either a fixed or random effect. Following the more recent suggestion, we thus modeled all predictors in our models as both main effects and as interactions with time (or predictors of the random slope) across all three social competence models. In HLM reduced-model notation, the final models were estimated as follows:

$$
\begin{aligned}
& Y_{t i k}=\left(\gamma_{000}\right)+\left(\beta_{10 k}{ }^{*} A G E_{t i k}\right)+\left(\beta_{01 k}{ }^{*} A L C\right. \\
&+\beta_{02 k}{ }^{*} S E X \\
&+\beta_{03 k}{ }^{*} A L C^{*} S E X \\
&+\beta_{11 k^{*}}{ }^{*} A L C^{*} A G E \\
&+\beta_{12 k}{ }^{*} S E X^{*} A G E \\
&\left.+\beta_{13 k}{ }^{*} A L C^{*} S E X^{*} A G E\right) \\
&+\left(U_{00 k}+r_{0 i k}+r_{1 i k}+e_{t i k}\right)
\end{aligned}
$$
}

where $Y$ represents the outcome, $t$ represents time, $i$ represents individual children, $k$ represents family, $\gamma 000$ represents the fixed intercept, $\beta_{10 k}$ represents the fixed slope, all other $\gamma_{p q k}$ represent the main and interactive effects of individual predictors on social competence, $A L C$ represents parent alcoholism, $U_{O O k}$ represents the random effect for intrafamilial variation in social competence, $r_{0 i k}$ represents the random effect for the intercept, $r_{l i k}$ represents the random effect for the slope, and $e$ represents residual variance. 
testing such interactions are described in detail in Curran, Bauer, \& Willoughby, in press). Girls with alcoholic fathers self-reported less social competence at age 6 compared with girls without alcoholic fathers $(\beta=-.48), t(367)=-2.27, p<.05$, whereas boys with and without alcoholic fathers did not differ from one another in their social competence at age 6 $(\beta=.08), t(367)=0.56, n s$.

An interaction between child's gender and the recency of parent alcoholism predicting the intercept of self-reported social competence trajectories was also found. Though no differences in self-reported social competence were found for those without an alcoholic parent and those whose parents had recovered from alcoholism, children with a recently alcoholic parent differed from those without an alcoholic parent as a function of child gender. Specifically, girls with a recently alcoholic parent reported less social competence at age 6 than did girls with nonalcoholic parents $(\beta=-.52), t(367)=-2.47, p<.05$. No effect of parent alcoholism was found on boys' self-reported social competence $(\beta=.01), t(367)=$ $0.12, n s$.

The interaction between child's gender and the number of alcoholic parents also predicted the intercept of trajectories of self-reported social competence. Probing of this interaction showed that having more alcoholic parents predicted lower self-reported social competence in girls $(\beta=-.25), t(369)=-2.26, p<.05$, but not in boys $(\beta=.04), t(369)=0.62, n s$. No other effects of the number of alcoholic parents were found.

In the parent-reported social competence model, no main or interactive effects involving maternal and paternal alcoholism were found.4 Child's gender did predict the trajectory intercepts and significantly predicted the trajectory slopes, such that parents reported somewhat greater social competence at age 6 but decreasing rates of change in boys compared with girls. No effects of the number of alcoholic parents or recency of parent alcoholism were found for parent-reported social competence trajectories.

In the teacher-reported models of social competence, paternal alcoholism interacted with child's gender to predict both trajectory intercepts and slopes. No effects of maternal alcoholism were found. Probing of the finding for paternal alcoholism showed that teachers reported lower social competence at age $6(\beta=-.62), t(367)=-3.58, p<.001$, and less decreasing slopes over time $(\beta=.10), t(367)=2.95, p<.01$, for girls with alcoholic fathers than for girls without alcoholic fathers. For boys, teacher reports of social competence at age $6(\beta=-.08), t(367)=-0.55, n s$, and of changes in social competence over time $(\beta=-.03)$, $t(367)=-1.40, n s$, did not differ for those with and without an alcoholic father. (See Figure 2 for estimated trajectories depicting these results.)

Recency of parent alcoholism also interacted with child's gender to predict teacher-reported social competence. Girls with recent alcoholic parents showed less social competence at age $6(\beta=-.79), t(367)=-3.64, p<.001$, and less steep decreases in social competence over time $(\beta=.07), t(367)=1.99, p<.05$, compared with girls whose parents were never diagnosed with alcoholism. Boys with a recent alcoholic parent versus nonalcoholic parents did not differ from one another in their social competence at age $6(\beta=-.10), t(367)=$ $-0.65, n s$, or in their rates of change in social competence over time $(\beta=-.03), t(367)=$ $-1.10, n s$. (Estimated trajectories for groups defined by child gender and recency of parent alcoholism are plotted in Figure 3.) No differences were found between children whose

\footnotetext{
${ }^{4}$ We tested the impact of scale reliability by replicating our models within a latent growth curve modeling framework using Mplus (Muthén \& Muthén, 1998) for the parent report model, where we corrected for unreliability in the measurement structure. No substantive changes in key findings emerged.
} 
parents had recovered from alcoholism prior to the past 3 years and children whose parents were never diagnosed as alcoholic.

The number of alcoholic parents also interacted with child gender in predicting the intercepts and (marginally) the slopes of teacher-reported social competence trajectories. Teachers reported less social competence at age $6(\beta=-.36), t(369)=-2.84, p<.01$, and marginally less steep slopes $(\beta=.04), t(369)=1.75, p<.10$, in girls with more alcoholic parents. Among boys, the number of alcoholic parents was unrelated to both teacher reports of age 6 social competence $(\beta=-.08), t(369)=-0.93, n s$, and to change in social competence over time $(\beta=-.01), t(369)=-0.69, n s$.

\section{Discussion}

In contrast to a literature focused on the development of deficits and psychopathology in atrisk youth, the current study focused on resilience as evident through the development of social competence in children at risk for psychopathology due to having an alcoholic parent. HLMs revealed different patterns of change in social competence across development as a function of the reporter of various indicators of social competence. Moreover, female COAs compared with female non-COAs showed lower social competence in early childhood that receded in adolescence and that varied across subtypes of parent alcoholism. We discuss each of these findings in turn before focusing on implications for understanding the development of social competence more generally.

\section{Trajectories of Social Competence}

As just noted, a key finding was that the form of normative trajectories of social competence varied as a function of the observer and specific indicator of the child's social competence. Given differences in the subcomponents of social competence tapped by measures given to different reporters, however, we could not disentangle these two sources of variance in our findings. We thus discuss the findings as they relate to previous studies on reporter effects and then with respect to other measurement issues across reporters.

Largely consistent with the limited literature, social competence increased over time when assessed by child's self-report and showed no change over time when assessed by teachers' report (Chan et al., 2000; Cole, Jacquez, \& Maschman, 2001; Cole, Maxwell, et al., 2001). Although evidence of interindividual differences in social competence upon school entry was found regardless of reporter, only children's and parents' reports of social competence showed interindividual differences in intraindividual change over time. As such, teacher reports of social competence at age 6 were highly predictive of how socially competent teachers perceived children to be into adolescence.

Reporter differences in trajectories of social competence may be a function of the items given to each reporter, the changing expectations of each reporter for social competence with the child's age, the changing experience of teachers and parents as children succeed or fail at different, age-graded role demands, and, for teacher-reports in particular, changes in the social context in which such behaviors are observed. Items assessing teacher report of social competence focused on making friends, popularity, and possessing socially desirable traits. Given stability in average levels of social competence over time (i.e., average intraindividual stability), these items may be reliable indicators of social competence at any age, although the skills needed to have friends and the experience of these friendships themselves are likely to change significantly over time. Moreover, self-reported social competence items focused on making friends and popularity but also on satisfaction with social relationships. Perhaps as adolescents become more active participants in selecting and shaping their social experiences, it is their satisfaction with their social competence that 
increases over time, creating an average increasing pattern of intraindividual change in selfreported social competence over time.

Changing expectations and social settings may also impact trajectories of social competence over time. This is perhaps most easily illustrated with teacher reports. As children enter new school environments, such as the transition to middle school, teachers change as do teacher expectations for behavior and institutionally imposed consequences and restraints on behavior (Eccles et al., 1989; Wigfield et al., 1991). Disruption of peer networks and of how teachers interact with students may impact teacher ratings of social competence over time. Although our teacher reports of social competence reflect changes in reporters as well as changes in the child's development, teachers are not able to rate social development in children with respect to their past accomplishments but must rely on the social behavior of other children for comparison. This perhaps makes teachers better reporters of interindividual than of intraindividual change in social competence. Nonetheless, the degree of average intraindividual stability was striking in the current study.

\section{COAs and Social Competence}

Consistent with our hypothesis, COAs showed deficits in both self-reported and teacherreported social competence. However, this effect was limited as a function of child gender and heterogeneity among COAs. These results led us to three key findings. First, gender differences in social competence deficits associated with parent alcoholism indicated that this risk is specific to girls. Given that many of the early negative outcomes in COAs have been documented primarily in boys or found to be more likely to occur in boys (Fitzgerald, Zucker, Puttler, Caplan, \& Mun, 2000; Puttler et al., 1998), the current finding urges researchers to cast a broader net in assessing adjustment indicators when evaluating gender differences in risk associated with parent alcoholism. Gender socialization theory would suggest that a greater emphasis on social skills development in girls may create different expectations for social competence in boys and girls, leading others to judge deficits in girls more harshly. This possibility is supported not only by the pattern of gender differences in teacher reports at age 6 but also by greater reported social competence in girls than in boys from nonalcoholic families, reflecting the expected difference. To the extent that girls also internalize these gender-related expectations for social interaction, this same pattern of gender differences should emerge in the self-reports of social competence, a prediction consistent with the current findings.

Second, early deficits in social competence at age 6 disappeared over time, an effect driven by relatively greater decreases in low-risk, rather than high-risk, girls' social competence. The decrease in self-reported social competence over time in girls may reflect a lessening of the need for normative ego-protective mechanisms with increasing age. As suggested in work regarding social skills in children with attention-deficit/hyperactivity disorder, young children have a tendency to overestimate their competence (Gresham, Lane, MacMillan, Bocian, \& Ward, 2000). Given the emphasis on social skills associated with the female gender role, this tendency may be more evident in girls than in boys for the particular domain of social competence. This overestimation is posited to protect young children's self-esteem, permitting children the opportunity to enact new skills, to suffer setbacks with fewer repercussions, and to explore their social interactions in a manner that maintains selfconfidence and ego resilience. As children develop, their more advanced metacognitive skills (e.g., perspective taking, social comparison) and experiences yield to more realistic estimations of social competence, resulting in decreasing social competence over time as is evident in low-risk girls in the current study. Absence of this protective mechanism in young female COAs may thus reflect a point of vulnerability in early childhood. 
In a second, potentially co-occurring, mechanism, female COAs may not show the same levels of social competence as their female peers because of early risk for externalizing and internalizing symptomatology or temperament-related difficulties. For COA boys, the normative style of rough and tumble play characterizing peer interactions as well as different thresholds over time for friendship interactions may result in fewer problems in developing normative levels of social competence. As low-risk girls develop a greater emphasis on dyadic friendships and patterns of relational aggression and exclusion arise in early adolescence as a normative style of peer interaction, the relative advantage in social competence of these girls over female COAs may diminish.

Third, not all COAs manifested risk for early social competence deficits; rather, this effect was most evident in those with paternal rather than maternal alcoholism, recent as opposed to recovered alcoholic parents, and having two alcoholic parents rather than one. As suggested by Zucker, Wong, Puttler, and Fitzgerald (2003), such findings call for a more differentiated definition of risk in the study of resilience. Having an active alcoholic parent, or having two alcoholic parents, may increase risk for social competence deficits due to the greater stress and chaos in the home environment and the more direct observation of parental problems, including social interaction deficits characterizing the parent-child relationship (Loukas, Zucker, Fitzgerald, \& Krull, 2003). Notably, children of parents who were recovered alcoholics (i.e., had experienced alcoholism but not in the past 3 years) showed similar levels of social competence as children with nonalcoholic parents, suggesting that the risks associated with deficits in this domain may be more short term than those evident in other domains. Finally, paternal alcoholism has also been associated with greater risk for behavioral dysregulation and difficult temperament, perhaps related to a genetic liability, each of which may increase risk for social competence deficits as well (Tarter et al., 1999). Our results suggest that not all COAs manifest risk or resilience similarly and that part of the difference in outcomes within this risk group may be due to heterogeneity in the type of alcoholism in the family and in the gender of the child (Zucker, Fitzgerald, \& Moses, 1995).

\section{Conclusions}

The current findings point to the need for finer-grained analyses that may better differentiate the development of various dimensions of social competence over time as a function of social context and societal expectation. This study offers evidence that some COAs lag behind their peers in the development of social competence. This evidence is found in the self- and teacher reports of girls. Strengths of the current study that lend support to these findings include the use of a community-based, high-risk sample, inclusion of multiple reporters of social competence, and the longitudinal assessment of these youth. However, limitations of the study include the use of nonparallel measures of social competence across reporters and low reliability of the parent report measure of social competence. Although the small size of certain subsamples of children (e.g., girls in nonalcoholic families) may raise issues concerning generalizability, the attention to representativeness in sample recruitment and retention counter this potential limitation.

Given the modest effects of parent alcoholism and child gender on these indicators of social competence, other influences on and periods for change in the development of social competence over time should be considered. For example, future studies may want to include more fine-grained assessment around periods of greater fluctuations in social selfcompetence such as the transition to middle school (Eccles et al., 1989; Wigfield et al., 1991). Associated predictors may also provide greater insight into the factors that more clearly define resilient outcomes in the face of risk associated with parent alcoholism. Lessons for the study of risk and resilience offered by the current study include an emphasis 
on heterogeneity in the outcomes of social competence among COAs. Although some indicators of parent alcoholism were associated with greater deficits in social competence (e.g., paternal alcoholism, having a greater number of alcoholic parents, and having more recent parent alcoholism), others were not. Moreover, parent alcoholism appears to have a time-limited influence on social competence, perhaps suggesting the presence of more proximal influences that distinguish among the resilient and distressed COAs in adolescence. Consistent with other areas of study within the field of resilience, research to identify developmentally linked mediational mechanisms that account for variability in adolescent social competence among this risk group is needed (Zucker et al., 2003).

This study contributes to our understanding of social competence in general and to the complexities that are inherent in studying the development of competence in a high-risk population. Although the predictors of parent alcoholism and children's gender account for only small to moderate variance in the social development outcomes, the results contribute to a very limited literature on prosocial outcomes among high-risk youth and thus add to their practical significance. In this case, risk is manifested as a delay in the development of normative social competence for female COAs. The extent to which such delays may be redressed through the use of social skills training curricula for these children is not yet known. Our findings suggest that such training may be beneficial if considered in conjunction with the specificity in risk for such targeted deficits in the daughters of a subset of alcoholic parents. However, what is not clear is whether such changes in social competence might be useful as well in addressing other areas of social risk for COAs, such as the tendency to associate with deviant peers. The intersection of social competence and this well-known risk factor for multiple negative outcomes associated with parent alcoholism is an important area of further inquiry.

\section{Acknowledgments}

Andrea M. Hussong received support from National Institute on Drug Abuse Grants DA12912 and DA15398 in the writing of this article. The work was also supported by National Institute on Alcohol Abuse and Alcoholism Grant R37 AA 07065 to Robert A. Zucker and Hiram E. Fitzgerald. We thank Susan Refior, study director of field operations, for her sustained effort and skill in sustaining this study's viability over such a long period of time. We also thank the participating families for their willingness to engage with us in what is an essentially altruistic activity, over so many years.

\section{References}

Achenbach TM. "Comorbidity" in child and adolescent psychiatry: Categorical and quantitative perspectives. Journal of Child and Adolescent Psychopharmacology. 1991; 1:271-278.

American Psychiatric Association. Diagnostic and statistical manual of mental disorders. 4th ed.. Washington, DC: Author; 1994.

Bagwell C, Newcomb A, Bukowski W. Preadolescent friendship and peer rejection as predictors of adult adjustment. Child Development. 1998; 69:140-153. [PubMed: 9499563]

Berndt, T.; Burgy, L. Social self-concept. In: Bracken, BA., editor. Handbook of self-concept: Developmental, social, and clinical considerations. Oxford, England: Wiley; 1996. p. 171-209.

Bingham CR, Fitzgerald WW, Fitzgerald HE, Zucker RA. Prenatal history, parental alcoholism, and the development of preschool aged sons of alcoholics [Abstract]. Alcoholism: Clinical and Experimental Research. 1996; 20:469.

Bracken, BA. The Multidimensional Self Concept Scale. Austin, TX: Pro-Ed.; 1992.

Chan D, Ramey S, Ramey C, Schmitt N. Modeling intraindividual changes in children's social skills at home and at school: A multivariate latent growth approach to understanding between-settings differences in children's social skill development. Multivariate Behavioral Research. 2000; 35:365396. 
Chassin L, Rogosch F, Barrera M. Substance use and symptomatology among adolescent children of alcoholics. Journal of Abnormal Psychology. 1991; 100:449-463. [PubMed: 1757658]

Coie, JD.; Belding, M.; Underwood, M. Aggression and peer rejection in childhood. In: Lahey, BB.; Kazdin, AE., editors. Advances in clinical child psychology. Vol. Vol. 11. New York: Plenum Press; 1988. p. 125-158.

Cole DA, Jacquez FM, Maschman TL. Social origins of depressive cognitions: A longitudinal study of self-perceived competence in children. Cognitive Therapy and Research. 2001; 25:377-395.

Cole DA, Maxwell SE, Martin JM, Peeke LG, Seroczynski AD, Tram JM, et al. The development of multiple domains of child and adolescent self-concept: A cohort sequential longitudinal design. Child Development. 2001; 72:1723-1746. [PubMed: 11768142]

Curran, PJ.; Bauer, DJ.; Willoughby, MT. Testing and probing interactions in hierarchical linear growth models. In: Bergeman, CS.; Boker, SM., editors. The Notre Dame Series on Quantitative Methodology: Vol. 1. Methodological issues in aging research. Mahwah, NJ: Erlbaum; (in press)

Curran PJ, Bollen KA, Paxton P, Kirby J, Chen FN. The noncentral chi-square distribution in misspecified structural equation models: Finite sample results from a Monte Carlo simulation. Multivariate Behavioral Research. 2002; 37:1-36.

Curran PJ, Chassin L. A longitudinal study of parenting as a protective factor for children of alcoholics. Journal of Studies on Alcohol. 1996; 57:305-313. [PubMed: 8709589]

Dishion TJ, Capaldi D, Spracklen KM, Li FZ. Peer ecology of male adolescent drug use. Development and Psychopathology. 1995; 7:803-824.

Eccles JS, Wigfield A, Flanagan CA, Miller C, Reuman DA, Yee D. Self-concepts, domain values, and self-esteem-Relations and changes at early adolescence. Journal of Personality. 1989; 57:283-310. [PubMed: 2769558]

Fitzgerald HE, Sullivan LA, Ham HP, Zucker RA, Bruckel S, Schneider AM, et al. Predictors of behavior problems in three-year-old sons of alcoholics: Early evidence for the onset of risk. Child Development. 1993; 64:110-123. [PubMed: 7679621]

Fitzgerald HE, Zucker RA, Puttler LI, Caplan HM, Mun E-Y. Alcohol abuse/dependence in women and girls: Etiology, course, and subtype variations. Alcoscope: International Review of Alcoholism Management. 2000; 3:6-10.

Gresham FM, Lane KL, MacMillan DL, Bocian KM, Ward SL. Effects of positive and negative illusory biases: Comparisons across social and academic self-concept domains. Journal of School Psychology. 2000; 38:151-175.

Harter S. The Perceived Competence Scale for Children. Child Development. 1982; 53:87-97.

Harter, S. Manual for the Self-Perception Profile for Children. Denver, CO: University of Denver; 1985.

Harter, S. Manual for the Self-Perception Profile for Adolescents. University of Denver; 1988. Unpublished manuscript

Kalverboer, A. Follow-up of biological high-risk groups. In: Rutter, M., editor. Studies of psychosocial risk: The power of longitudinal data. New York: Cambridge University Press; 1988. p. 114-137.

Ladd G. Having friends, keeping friends, making friends, and being liked by peers in the classroom: Predictors of children's early school adjustment? Child Development. 1990; 61:1081-1100. [PubMed: 2209179]

Larsson B, Knutsson-Medin L, Sundelin C, Trost von Werder AC. Social competence and emotional/ behavioural problems in children of psychiatric inpatients. European Child \& Adolescent Psychiatry. 2000; 9:122-128. [PubMed: 10926062]

Ledingham JE. Recent developments in high-risk research. Advances in Clinical Child Psychology. 1990; 13:91-137.

Loehlin, JC. Latent variable models: An introduction to factor, path, and structural analysis. 2nd ed.. Hillsdale, NJ: Erlbaum; 1992.

Loukas A, Zucker RA, Fitzgerald HE, Krull JL. Developmental trajectories of disruptive behavior problems in sons of alcoholics: Effects of parent psychopathology, family conflict, and child undercontrol. Journal of Abnormal Psychology. 2003; 112:119-131. [PubMed: 12653420]

Marsh HW, O’Neill R. Self Description Questionnaire III. The construct validity of multidimensional self-concept ratings by late adolescents. Journal of Educational Measurement. 1984; 21:153-174. 
Masten AS, Coatsworth JD, Neemann J, Gest SD, Tellegen A, Garmezy N. The structure and coherence of competence from childhood through adolescence. Child Development. 1995; 66:1635-1659. [PubMed: 8556890]

Muthén, LK.; Muthén, BO. Mplus user's guide [Computer software and manual]. Los Angeles: Authors; 1998.

Noll RB, Zucker RA, Fitzgerald HE, Curtis WJ. Cognitive and motoric functioning of sons of alcoholic fathers and controls: The early childhood years. Developmental Psychology. 1992; 28:665-675.

Oetting ER, Beauvais F. Common elements in youth drug abuse: Peer clusters and other psychosocial factors. Journal of Drug Issues. 1987; 17(1-2):133-151.

Parker JG, Asher SR. Peer relations and later personal adjustment-Are low-accepted children at risk? Psychological Bulletin. 1987; 102:357-389. [PubMed: 3317467]

Parker JG, Asher SR. Friendship and friendship quality in middle childhood: Links with peer group acceptance and feelings of loneliness and social dissatisfaction. Developmental Psychology. 1993; 29:611-621.

Parker, JG.; Rubin, KH.; Price, JM.; DeRosier, ME. Peer relationships, child development, and adjustment: A developmental psychopathology perspective. In: Cicchetti, D.; Cohen, DJ., editors. Developmental psychopathology: Vol. 2. Risk, disorder, and adaptation. Oxford, England: Wiley; 1995. p. 96-161.

Piejak, LA.; Fitzgerald, HM.; Zucker, RA.; von Eye, A. Predictors of academic functioning of sons of male antisocial and nonantisocial alcoholics during the elementary school years. Michigan State University and University of Michigan; 2004. Unpublished manuscript

Pillow DR, Barrera M, Chassin LA. Using cluster analysis to assess the effects of stressful life events: Probing the impact of parental alcoholism on child stress and substance use. Journal of Community Psychology. 1998; 26:361-380.

Puttler LI, Zucker RA, Fitzgerald HE, Bingham CR. Behavioral outcomes among children of alcoholics during the early and middle childhood years: Familial subtype variations. Alcoholism: Clinical and Experimental Research. 1998; 22:1962-1972.

Raudenbush SW. Comparing personal trajectories and drawing causal inferences from longitudinal data. Annual Review of Psychology. 2001; 52:501-525.

Raudenbush, SW.; Bryk, AS. Hierarchical linear models: Applications and data analysis methods. 2nd ed.. Thousand Oaks, CA: Sage; 2002.

Robins, LN.; Helzer, JE.; Croughan, J.; Ratcliff, KS. The NIMH Diagnostic Interview Schedule: Its history, characteristics and validity. St. Louis, MO: Washington University School of Medicine; 1980.

Rockhill, CM. Depressed children's friendships. Poster session presented at the biennial meeting of the Society for Research in Child Development; Indianapolis, IN. 1995 March.

Rose-Krasnor L. The nature of social competence: A theoretical review. Social Development. 1997; 6:111-135.

Segrin C, Menees MM. The impact of coping styles and family communication on the social skills of children of alcoholics. Journal of Studies on Alcohol. 1996; 57:29-33. [PubMed: 8747498]

Selzer ML, Vinokur A, van Rooijan L. A self-administered short Michigan Alcoholism Screening Test (SMAST). Journal of Studies on Alcohol. 1975; 36:117-126. [PubMed: 238068]

Sher, KJ. Children of alcoholics: A critical appraisal of theory and research. Chicago: University of Chicago Press; 1991.

Sokol RJ, Claren SK. Guidelines for use of terminology describing the impact of prenatal alcohol on the offspring. Alcoholism: Clinical and Experimental Research. 1989; 13:597-598.

Tarter RE, Vanyukov M, Giancola P, Dawes M, Blackson T, Mezzich A, Clark DB. Etiology of early age onset substance use disorder: A maturational perspective. Development and Psychopathology. 1999; 38:115-142.

Waters E, Sroufe LA. Social competence as a developmental construct. Developmental Review. 1983; 3:79-97.

Werner EE. Resilient offspring of alcoholics: A longitudinal study from birth to age 18. Journal of Studies on Alcohol. 1986; 47:34-40. [PubMed: 3959559] 
West MO, Prinz RJ. Parental alcoholism and childhood psychopathology. Psychological Bulletin. 1987; 102:204-218. [PubMed: 3310059]

Wigfield A, Eccles JS, Maciver D, Reuman DA, Midgley C. Transitions during early adolescenceChanges in children's domain-specific self-perceptions and general self-esteem across the transition to junior high school. Developmental Psychology. 1991; 27:552-565.

Wong MM, Zucker RA, Fitzgerald HE, Puttler LI. Heterogeneity of risk aggregation for alcohol problems between early and middle childhood: Nesting structure variations. Development and Psychopathology. 1999; 11:727-744. [PubMed: 10624723]

Zucker RA, Fitzgerald HE. Early developmental factors and risk for alcohol problems. Alcohol Health and Research World. 1991; 15:18-24.

Zucker, RA.; Fitzgerald, HE.; Moses, HD. Emergence of alcohol problems and the several alcoholisms: A developmental perspective on etiologic theory and life course trajectory. In: Cicchetti, D.; Cohen, DJ., editors. Developmental psychopathology: Vol. 2. Risk, disorder, and adaptation. New York: Wiley; 1995. p. 677-711.

Zucker, RA.; Fitzgerald, HE.; Noll, RB. Drinking and drug history. Michigan State University; 1990. Unpublished manuscript

Zucker, RA.; Fitzgerald, HE.; Refior, SK.; Puttler, LI.; Pallas, DM.; Ellis, DA. The clinical and social ecology of childhood for children of alcoholics: Description of a study and implications for a differentiated social policy. In: Fitzgerald, HE.; Lester, BM.; Zuckerman, BS., editors. Children of addiction: Research, health and policy issues. New York: Routledge Falmer; 2000. p. 109-141.

Zucker, RA.; Wong, MM.; Puttler, LI.; Fitzgerald, HE. Resilience and vulnerability among sons of alcoholics: Relationship to developmental outcomes between early childhood and adolescence. In: Luthar, S., editor. Resilience and vulnerability: Adaptation in the context of childhood adversities. New York: Cambridge University Press; 2003. p. 76-103. 


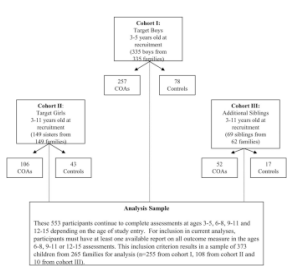

Figure 1.

Sample description. COAs $=$ children of alcoholic parents. 


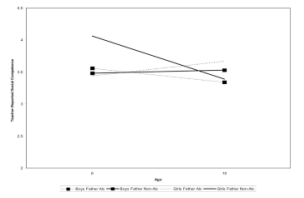

Figure 2.

Trajectories for teacher-reported social competence by father's alcoholism. Alc = alcoholic; Non-Alc $=$ nonalcoholic. 


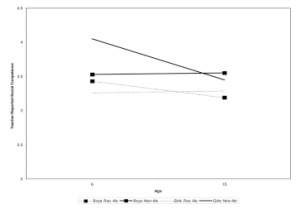

Figure 3.

Estimated trajectories for teacher-reported social competence by recency of parent alcoholism. Rec Alc = recent alcoholic parent; Non-Alc = nonalcoholic parent. 


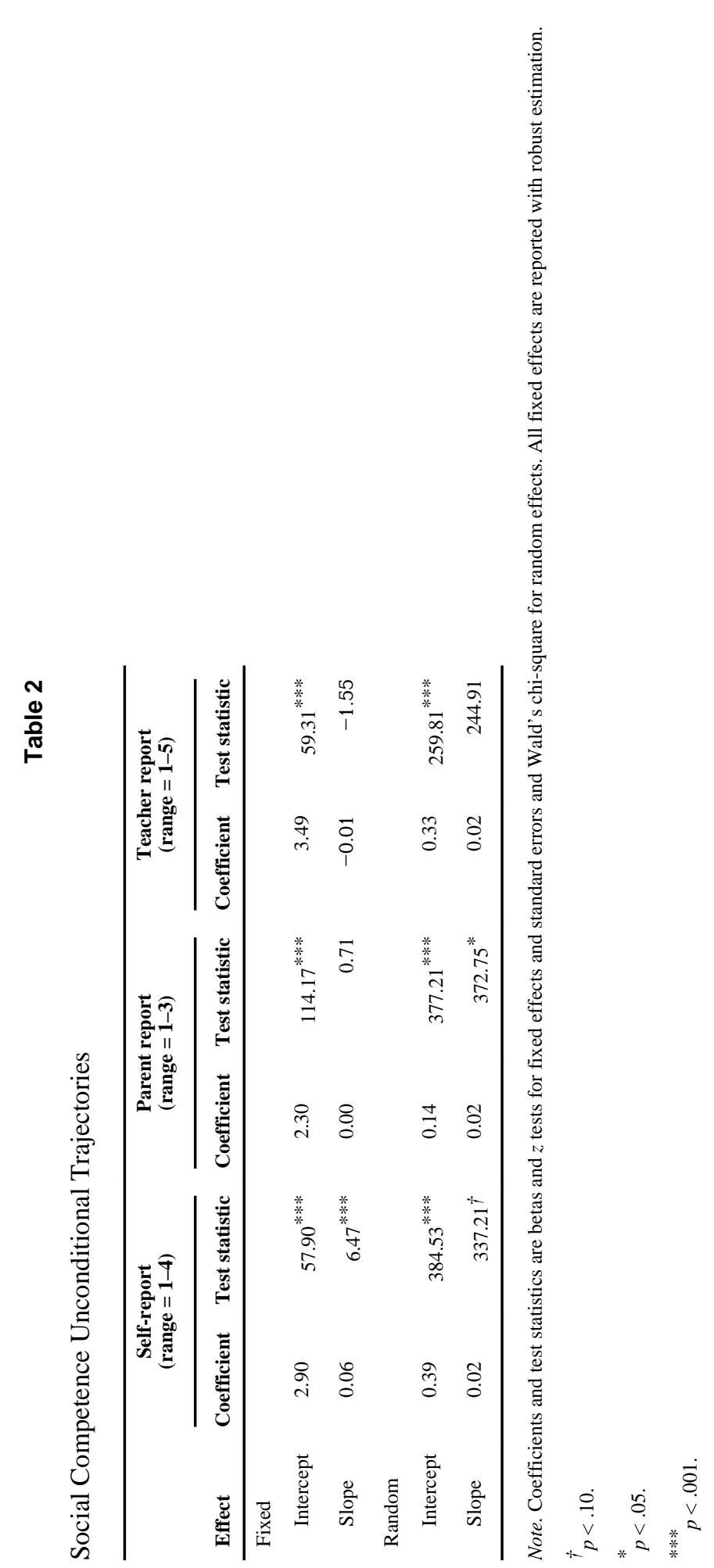

Dev Psychol. Author manuscript; available in PMC 2011 August 21. 


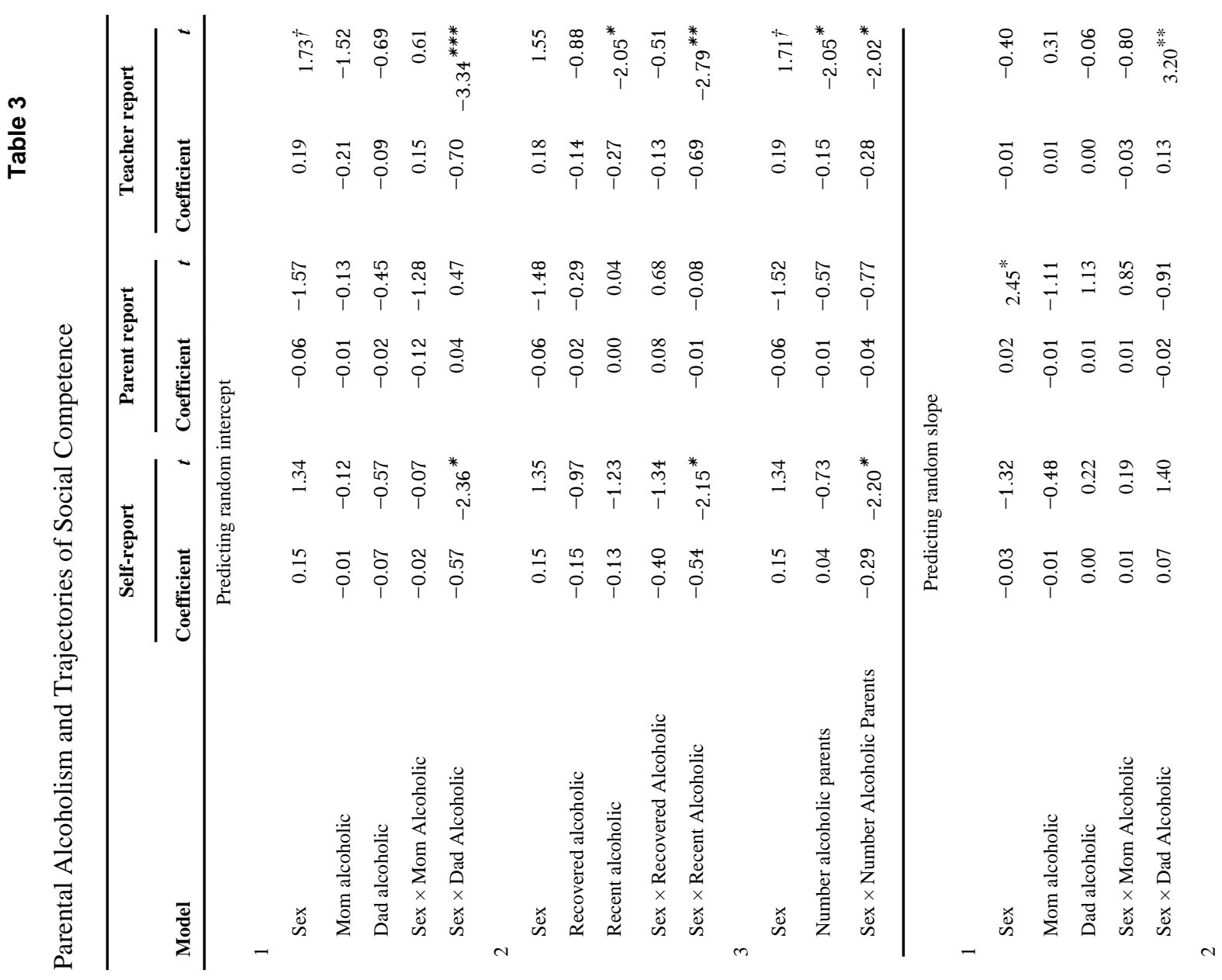




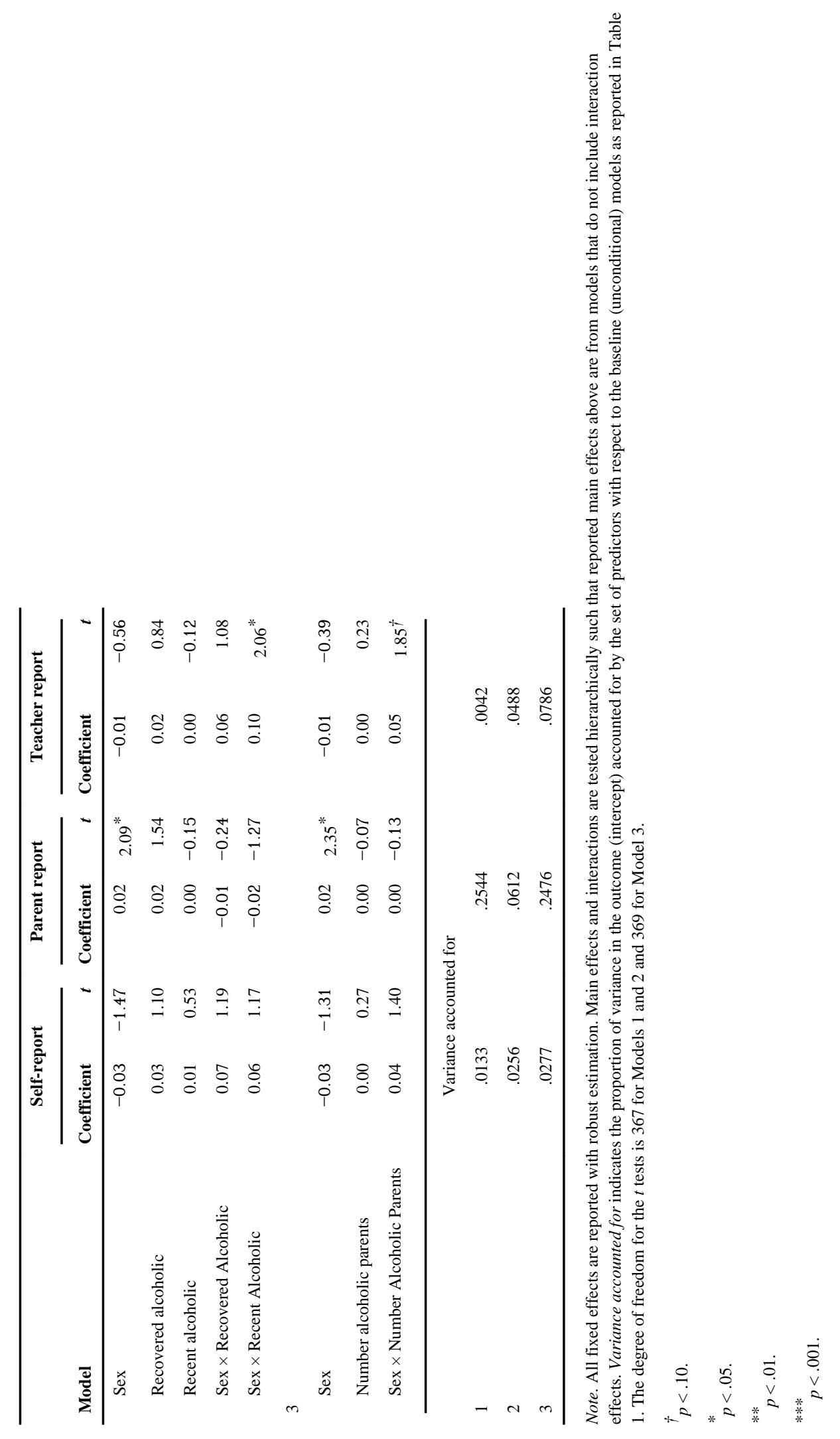

